\title{
Amoxycillin and Metronidazole Therapy for Helicobacter pylori Eradication: A 10-Year Trend in Turin, Italy
}

\author{
Davide Giuseppe Ribaldone1, Marco Astegiano1, Giorgio Saracco1,2, Rinaldo Pellicano1 \\ ${ }^{1}$ Gastroenterology Unit, S. Giovanni Battista (Molinette) Hospital, Turin, Italy \\ ${ }^{2}$ Department of Oncology, University of Turin, Turin, Italy
}

\section{To the Editor,}

Helicobacter pylori (H. pylori) infection plays a crucial role in causing gastritis and peptic ulcer disease (PUD). To date, despite the several regimens proposed, no therapy leads to a $100 \%$ H. pylori eradication rate (1). As the antimicrobial activity of metronidazole is marginally affected by low $\mathrm{pH}$, this drug may be highly effective against $H$. pylori. The European Helicobacter Study Group has advised to employ a metronidazole-based triple therapy as choice in treating $H$. pylori infection in relation to specific resistance rate in each region (2). Recently, a multicentric study revealed that, in Southern Europe, the primary rate of $H$. pylori metronidazole resistance was around 30\% (3).

In 2002, we found that in Turin, Northern Italy, a triple therapy with metronidazole, amoxycillin and a proton pump inhibitor (PPI) for 7 days or for 10 days, achieved an eradication rate of $73.5 \%$ or $71.6 \%$, respectively. Lengthening the treatment conferred no advantages. These values were significantly lower compared to those reported earlier (4). In a subsequent study with alternative schedules (cefixime plus metronidazole), the results did not improve (5). As antibiotic resistance is an evolving process, it is mandatory to carry out surveys in order to be guided in the therapeutic choice. Hence, in the year 2013 (January 01 - December 31), we evaluated prospectively the $H$. pylori eradication rate of consecutive naive patients, treated with a triple therapy comprising a standard dose of PPI, amoxycillin 1 $\mathrm{g}$ and metronidazole $500 \mathrm{mg}$ twice daily. Results were compared with a previous randomized prospective study conducted 10 years earlier with the same schedule (4). Eradication of $H$. pylori infection was assessed by ${ }^{13} \mathrm{C}$-urea breath test, performed according to the supplier's instructions (Helicobacter Test, $\mathrm{INFAI}^{\circledR}$, Bochum, Germany). The reported sensitivity is $97.9 \%$ and specificity $98.5 \%$. Samples were analysed for ${ }^{13} \mathrm{C} / 12 \mathrm{C}$ ratio with a mass spectrometer (BreathMAT plus, Finnigan, Bremen, Germany). Results were expressed as excess ${ }^{13} \mathrm{CO}_{2}$ excretion per mil: a value $>4$ delta per mil was considered positive. No patient had received PPI or antibiotics in the last 30 days. All patients gave their written informed consent. Differences in eradication rates were tested with the chi-square test (with Yates' correction for continuity). A $\mathrm{p}$ value $<0.05$ was considered significant. The cohort included 66 patients (40 males, mean age 61.6, range 39-62), 39 of them received a regimen including a 1 -week triple therapy (group I) and 27 were treated with a 10day triple therapy (group II). Forty-two of them had a previous diagnosis of PUD or gastroduodenal erosions, and the remaining of active gastritis. The overall $H$. pylori eradication rate was $69.2 \%(27 / 39)$ in group I and 70\% (19/27) in group II, without significant difference $(p=0.96)$. When compared with the prospective study published in the year 2002 (4) no differences were observed in the effectiveness of therapy ( $\mathrm{p}=0.81$ for 7 days and $\mathrm{p}=0.95$ for 10 days) (Table 1 ). In conclusion, in our area, a metronidazole-based treatment regimen for H. pylori eradication, although unsatisfactory, is as effective as 10 years ago.

TABLE 1. Results of $H$. pylori eradication regimens

\begin{tabular}{|c|c|c|c|c|c|}
\hline \multirow{3}{*}{$\begin{array}{l}\text { Treatment } \\
\text { PAM }\end{array}$} & \multicolumn{5}{|c|}{ H. pylori eradication $(\%)$} \\
\hline & \multicolumn{2}{|c|}{2002} & \multicolumn{2}{|c|}{2013} & \multirow[t]{2}{*}{$\mathrm{p}$} \\
\hline & & & & & \\
\hline 7 days & $39 / 53$ & $(73.5)$ & $27 / 39$ & $(69.2)$ & 0.81 \\
\hline \multicolumn{6}{|l|}{ PAM } \\
\hline 10 days & $38 / 53$ & $(71.6)$ & $19 / 27$ & $(70)$ & 0.95 \\
\hline
\end{tabular}

\footnotetext{
Address for Correspondence: Dr. Rinaldo Pellicano, Gastroenterology Unit, S. Giovanni Battista (Molinette) Hospital, Turin, Italy

Phone: ++39.11/6336240 e-mail: rinaldo_pellican@hotmail.com

Received: 3 January $2016 \quad$ Accepted: 2 October 2016 • DOI: 10.4274/balkanmedj.2015.1714

Available at www.balkanmedicaljournal.org

Cite this article as:

Ribaldone DG, Astegiano M, Saracco G, Pellicano R. Amoxycillin and Metronidazole Therapy for Helicobacter pylori Eradication: A 10-Year Trend in Turin, Italy. Balkan Med J 2017;34:290-1

${ }^{\circ}$ Copyright 2017 by Trakya University Faculty of Medicine / The Balkan Medical Journal published by Galenos Publishing House.
} 
Conflict of Interest: No conflict of interest was declared by the authors.

\section{REFERENCES}

1. Tursi A, Elisei W, Giorgetti G, Picchio M, Brandimarte G. Decreasing efficacy of the standard seven-day triple therapy containing amoxycillin and clarithromycin in curing Helicobacter pylori infection in clinical setting in Italy: a 10-year follow-up study. Panminerva Med 2014;56:57-61.

2. Malfertheiner P, Megraud F, O'Morain CA, Atherton J, Axon AT, Bazzoli F, et al. Management of Helicobacter pylori infection: the Maastricht IV/ Florence Consensus Report. Gut 2012;61:646-64.
3. Mégraud F, Coenen S, Versporten A, Kist M, Lopez-Brea M, Hirschl $\mathrm{AM}$, et al. Helicobacter pylori resistance to antibiotics in Europe and its relationship to antibiotic consumption. Gut 2013;62:34-42.

4. Pellicano R, Palmas F, Ponzetto A, Astegiano M, Smedile A, Morgando A, et al. Decreasing eradication rate of Helicobacter pylori infection with metronidazole-based triple therapy. A randomised study. Minerva Gastroenterol Dietol 2002;48:265-70.

5. Adriani A, Astegiano M, Smedile A, Rizzetto M, Pellicano R. Efficacy of cefixime plus metronidazole therapy for Helicobacter pylori eradication: a retrospective study. Minerva Med 2013;104:495-6. 